\section{Carcinoma of Tongue and Oropharynx}

\author{
Vijayendranath Nayak ${ }^{1 *}$, Raghavendra Kini ${ }^{2}$, Prasanna Kumar \\ Rao $^{2}$, Roopashri Rajesh Kashyap ${ }^{2}$, Gowri Bhandarkar ${ }^{2}$ and \\ Ujwala Shetty ${ }^{2}$
}

${ }^{1}$ Department of Oral Medicine and Radiology, Viveka Dental Clinic, Mangaluru, Bangalore, India

${ }^{2}$ Department of Oral Medicine and Radiology, AJ Institute of Dental Sciences, Mangaluru, Bangalore, India

\begin{abstract}
Oral cancer is $6^{\text {th }}$ most common malignancy globally. Tongue being an muscular organ and also the common site for cancerous lesion of which squamous cell carcinoma being the most reported form of cancer with respect to tongue. Lateral border of the tongue is the commonest site affected. Here we report a case of squamous cell carcinoma of the tongue affecting the lateral border.
\end{abstract}

Keywords: Cancer; Carcinoma; Squamous cell carcinoma; Tongue

\section{Introduction}

Carcinoma of the tongue is constitutes about $3 \%$ of all cancer affecting the human population globally. Tobaccouse mainly in the form of cigarettes or smokeless form is one of the predominant factors affecting the patients with tongue cancer [1]. Prevalence of oral cancer is two to three times more in men than women all over the world. In the reports issued globally, cancers of all regions of the oral cavity and pharynx are grouped and collectively represent the sixth most common cancer in the world affecting the human population [2]. Here we report a case of carcinoma of tongue affecting the posterior part of the tongue involving the oropharynx.

\section{Case Report}

A 61 year old male patient reported to the department of oral medicine and radiology with a chief complain of a wound on the left side of the tongue since 1 month. Initially the wound appeared like a small nodule 1month ago which was slowly progressive and attained

*Corresponding author: Vijayendranath Nayak, Department of Oral Medicine and Radiology, Viveka Dental Clinic, Mangaluru, Bangalore, India, Tel: +918197588777; E-mail: drnayakomr@gmail.com

Citation: Nayak V, Kini R, Rao PK, Kashyap RR, Bhandarkar G, et al. (2019) Carcinoma of Tongue and Oropharynx. J Dent Oral Health Cosmesis 4: 011.

Received: June 04, 2019; Accepted: August 7, 2019; Published: August 14, 2019

Copyright: (c) 2019 Nayak V, et al. This is an open-access article distributed under the terms of the Creative Commons Attribution License, which permits unrestricted use, distribution, and reproduction in any medium, provided the original author and source are credited. present size. Patient gave no history of difficulty in speech, swallowing and bleeding from the wound. Past medical history was non-contributory, Patient gave a history of extraction one month ago of the lower left back tooth. Brushes once daily consumes alcohol occasionally since thirty years. A solitary left submandibular lymph node was palpable measuring about one $\mathrm{cm}$ in diameter and non-tender. Intraoral examination revealed a solitary ulcero-proliferative growth on left lateral border of the tongue measuring $2.5 \mathrm{~cm}$ in diameter with rolled edges and yellowish slough over the surface.Areas of erythema seen on the borders. Extension of the ulceration is into the floor of the mouth and oropharyngeal region. Base of the ulcer was indurated and non-tender on palpation (Figure 1). A provisional diagnosis of carcinoma of the tongue was considered. Toluidine blue staining was performed and was positive. Incisional biopsy was performed and histopathological section revealed, epithelial cells with cellular and nuclear pleomorphism and altered nuclear cytoplasm mitotic figures sheets and islands invasion into salivary gland and skeletal muscles (Figure 2). A final diagnosis of moderately differentiated squamous cell carcinoma of the tongue was given. Surgical excision and followed by chemotherapy was advised and patient was recalled after a week. Patient was not keen of undergoing treatment, but after six months demise of the patient was informed by the concerned family relatives.

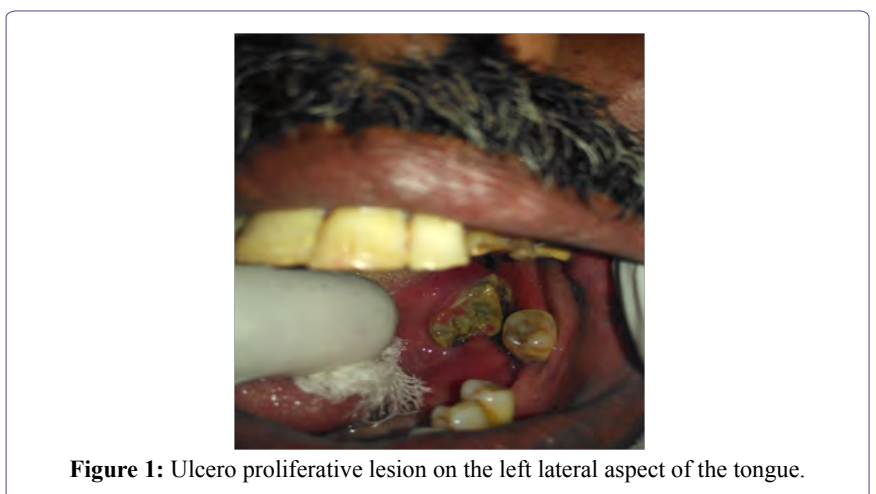

Figure 1: Ulcero proliferative lesion on the left lateral aspect of the tongue.

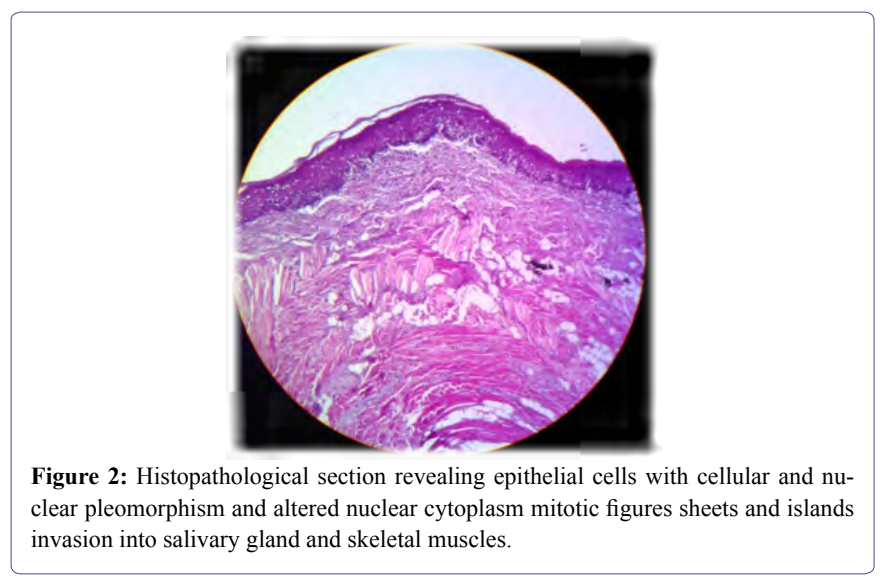




\section{Discussion}

Carcinoma of the tongue is one of the most commonly occurring neoplasms among all oral tumors i.e. Thirtypercent of all the intraoral malignancies [3]. Increase in use of tobacco can increase the chances of cancerous catastrophe. Other ethology is dental trauma due to presence of a sharp tooth edge, which could be traumatic with the predisposing factors which can cause oral cancer. A study reported that $44 \%$ of patients with carcinoma of tongue had a site of persistent mechanical irritation by sharp teeth or dentures, hence we can conclude that trauma is also a factor responsible for cancer in oral cavity [4].

Factors affecting that promote oral cancer includes, tobacco, diet, nutrition, viruses, radiation, alcohol, familial and genetic predisposition, candidiasis, immunosuppression, syphilis, dental factors, andoccupational risks [5]. The above reported case, patient gave only history of alcohol consumption. Alcoholic beverages have been considered carcinogenic to humans causing in, tumors of the oral cavity along with tumors of GIT which include pharynx, larynx, esophagus, and liver; although ethanol has not been proven carcinogenic in animal studies, yet it is considered to be a factor [6]. The role of alcohol as an independent factor in oral carcinogenesis is still unclear but the epidemiological evidence establishes the synergistic role played by alcohol along with tobacco. Alcohol increases the permeability of oral mucosaby producing an alteration in morphology of epithelium which is characterized by epithelial atrophy, which in turn leads to easier penetration of carcinogens into the oral mucosa [7].

Management of oral cancer can be done in many ways with prolonging the life of patients with minimum discomfort. Among the approaches to the treatment of squamous cell carcinoma affecting the tongue includes surgery, radiation therapy like external beam radiotherapy and brachytherapy, coadjutant therapy with the use of chemotherapeutic agents such as cisplatin, carboplatin, 5-fluorouracil, paclitaxel and docetaxel $[8,9]$.

Clinical and radiological assessment plays a major role in assessment of the primary tumor and areas of lymphatic drainage often understage disease in comparison with pathological assessment. Tumor control depends on two major factors, the extent and location of primary tumors along with the status of the neck lymph nodes which is the most important prognostic factor [10]. A higher risk of contralateral metastasis in patients with tumors of the floor of the mouth and the anterior third of the tongue compared to the retromolar region has been reported.In relation to tongue carcinomas, the importance of primary tumor invasion across the midline has already been stated. According to Martin, et al., 16\% of the tumors crossing the midline by less than $1 \mathrm{~cm}$ developed contralateral lymph node relapse, and this valueconsiderably increases to $46 \%$ in cases that invade over the midline by more than $1 \mathrm{~cm}$ due to the involvement of contralateral lymphatic drainage [11].

There is good amount of research papers published which can help us in understanding the causes to prevent a third of all cancers in the world and with this sufficient information to enable early detection and well-timed treatment of another third of cases[12]. Until today, there is no specific biomarkers for oral cancer, yet few latest studieshave showed that elevated levels of interleukin-8 and SAT can categorize between patients with oral squamous cell carcinoma and healthy patients, with high sensitivity and specificity [13]. Research should be carried for specific biomarkers for the disease so that defining the susceptibility field for etiological factors and their interaction.

\section{Conclusion}

Early detection, Health education and appropriate treatment planning should be considered to be most important priority in order to prevent this life threatening disease. We as dentist play a major role in counselling of the patients who are already affected guiding them for few psychological sessions so that patient is aware and starts the treatment as early as possible.

\section{References}

1. McQuarrie DG (1986) Cancer of the tongue: Selecting appropriate therapy. CurrProblSurg23:561-653.

2. Warnakulasuriya S (2009) Global epidemiology of oral and oropharyngeal cancer. Oral Oncol45: 309-316.

3. Ramirez-Amador V, Esquivel-Pedraza L, Ochoa-Carrillo FJ , Cuapio-Ortiz A , Frias-Mendivil M, et al. (1995) Cancer of the Mobile Tongue in Mexico: A Retrospective Study of 170 Patients. Eur J Cancer B Oral Oncol. 31:37-40.

4. Lockhart PB, Norris CM (1998) Pulliam C Dental factors in the genesis of squamous cell carcinoma of the oral cavity. Oral Oncol 34:133-139.

5. Kumar M, NanavatiR, Modi TG, Dobariya C (2016)Oral cancer: Etiology and risk factors: A review.J Cancer Res Ther12:458-463.

6. International Agency for Research on Cancer (1985) IARC monographs on the evaluation of the carcinogenic risks to humans: Tobacco habits other than smoking; betel- quid and areca-nut chewing; and some areca-nut-derived nitrosamines. IARC 37: 188.

7. International Agency for Research on Cancer (2002) IARC Monographs on the Evaluation of Carcinogenic Risks to Humans. IARC 83.

8. Huang SH, O'Sullivan B (2013) Oral cancer: Current role of radiotherapy and chemotherapy. Med Oral Patol Oral Cir Bucal. 18: 33-240.

9. Rivera C (2015)The challenge of the state of susceptibility to oral cancer. J Oral Res 4: 8-9.

10. Kumar M, Umashankar DN, Sharma R, Girish G (2011)Carcinoma of Anterior Two Third of the Tongue: A Case Report. Int J Oral MaxillofacPathol 2:55-58.

11. González-García R, Naval-Gías L, Sastre-Pérez J, Rodríguez-Campo FJ, Muñoz-Guerra MF, at al. (2007) Contralateral lymph neck node metastasis of primary squamous cell carcinoma of the tongue: a retrospective analytic study of 203 patients.Int J Oral MaxillofacSurg 36:507-513.

12. Petersen PE (2009) Oral cancer prevention and control-the approach of the World Health Organization. Oral Oncol. 45: 454-460.

13. Elashoff D, Zhou H, Reiss J, Wang J, Xiao H, et al. (2012) Prevalidation of salivary biomarkers for oral cancer detection. Cancer Epidemiol Biomarkers Prev 21: 664-672. 


\section{II}

Journal of Anesthesia \& Clinical Care

Journal of Addiction \& Addictive Disorders

Advances in Microbiology Research

Advances in Industrial Biotechnology

Journal of Agronomy \& Agricultural Science

Journal of AIDS Clinical Research \& STDs

Journal of Alcoholism, Drug Abuse \& Substance Dependence

Journal of Allergy Disorders \& Therapy

Journal of Alternative, Complementary \& Integrative Medicine

Journal of Alzheimer's \& Neurodegenerative Diseases

Journal of Angiology \& Vascular Surgery

Journal of Animal Research \& Veterinary Science

Archives of Zoological Studies

Archives of Urology

Journal of Atmospheric \& Earth-Sciences

Journal of Aquaculture \& Fisheries

Journal of Biotech Research \& Biochemistry

Journal of Brain \& Neuroscience Research

Journal of Cancer Biology \& Treatment

Journal of Cardiology: Study \& Research

Journal of Cell Biology \& Cell Metabolism

Journal of Clinical Dermatology \& Therapy

Journal of Clinical Immunology \& Immunotherapy

Journal of Clinical Studies \& Medical Case Reports

Journal of Community Medicine \& Public Health Care

Current Trends: Medical \& Biological Engineering

Journal of Cytology \& Tissue Biology

Journal of Dentistry: Oral Health \& Cosmesis

Journal of Diabetes \& Metabolic Disorders

Journal of Dairy Research \& Technology

Journal of Emergency Medicine Trauma \& Surgical Care

Journal of Environmental Science: Current Research

Journal of Food Science \& Nutrition

Journal of Forensic, Legal \& Investigative Sciences

Journal of Gastroenterology \& Hepatology Research

Journal of Gerontology \& Geriatric Medicine
Journal of Genetics \& Genomic Sciences

Journal of Hematology, Blood Transfusion \& Disorders

Journal of Human Endocrinology

Journal of Hospice \& Palliative Medical Care

Journal of Internal Medicine \& Primary Healthcare

Journal of Infectious \& Non Infectious Diseases

Journal of Light \& Laser: Current Trends

Journal of Modern Chemical Sciences

Journal of Medicine: Study \& Research

Journal of Nanotechnology: Nanomedicine \& Nanobiotechnology

Journal of Neonatology \& Clinical Pediatrics

Journal of Nephrology \& Renal Therapy

Journal of Non Invasive Vascular Investigation

Journal of Nuclear Medicine, Radiology \& Radiation Therapy

Journal of Obesity \& Weight Loss

Journal of Orthopedic Research \& Physiotherapy

Journal of Otolaryngology, Head \& Neck Surgery

Journal of Protein Research \& Bioinformatics

Journal of Pathology Clinical \& Medical Research

Journal of Pharmacology, Pharmaceutics \& Pharmacovigilance

Journal of Physical Medicine, Rehabilitation \& Disabilities

Journal of Plant Science: Current Research

Journal of Psychiatry, Depression \& Anxiety

Journal of Pulmonary Medicine \& Respiratory Research

Journal of Practical \& Professional Nursing

Journal of Reproductive Medicine, Gynaecology \& Obstetrics

Journal of Stem Cells Research, Development \& Therapy

Journal of Surgery: Current Trends \& Innovations

Journal of Toxicology: Current Research

Journal of Translational Science and Research

Trends in Anatomy \& Physiology

Journal of Vaccines Research \& Vaccination

Journal of Virology \& Antivirals

Archives of Surgery and Surgical Education

Sports Medicine and Injury Care Journal

International Journal of Case Reports and Therapeutic Studies

Submit Your Manuscript: http://www.heraldopenaccess.us/Online-Submission.php 